\title{
JNK inhibitor SP600125 enhances TGF- $\beta$-induced apoptosis of RBE human cholangiocarcinoma cells in a Smad-dependent manner
}

\author{
YOUZHI LIN ${ }^{1}$, BINHAO ZHANG ${ }^{1}$, HUIFANG LIANG ${ }^{1}$, YULEI LU ${ }^{2}$, XI AI $^{1}$, \\ BIXIANG ZHANG ${ }^{1}$ and XIAOPING CHEN ${ }^{1}$
}

${ }^{1}$ Hepatic Surgery Center, Tongji Hospital, Tongji Medical College, Huazhong University of Science and Technology,
Wuhan, Hubei 430030; ${ }^{2}$ Tumor Hospital of Guangxi Medical University, Nanning, Guangxi 530021, P.R. China

Received April 21, 2013; Accepted September 25, 2013

DOI: $10.3892 / \mathrm{mmr} .2013 .1711$

\begin{abstract}
Transforming growth factor $\beta$ (TGF- $\beta$ ) signaling is pivotal for the progression of specific types of tumors at certain stages. However, the mechanism by which TGF- $\beta$ is regulated by other factors remains unclear. In this study, the involvement of SP600125, an inhibitor of c-Jun N-terminal kinase (JNK), in TGF- $\beta$-induced apoptosis of the RBE human cholangiocarcinoma cell line was investigated. Exogenous TGF- $\beta 1$ activated Smad and non-Smad signaling pathways, including the JNK pathway in RBE cells, and induced apoptosis, which was inhibited by knockdown of Smad4 expression. SP600125 increased the TGF- $\beta 1$-induced phosphorylation of Smad 2 and Smad3, which enhanced the TGF- $\beta 1$-induced transcriptional response and apoptosis in RBE cells. The effect of SP600125 on the transcriptional response and apoptosis was reduced by knockdown of Smad4 expression. In addition, TGF- $\beta 1$-induced apoptosis was abrogated using the pan-caspase inhibitor Z-VAD-fmk. SP600125 promoted the TGF- $\beta 1$-induced caspase cleavage, while knockdown of Smad4 expression counteracted this effect. These results indicate that SP600125 enhances TGF- $\beta$-induced apoptosis of RBE cells through a Smad-dependent pathway that involves Smad-dependent caspase activation. SP600125 is hypothesized to be an ideal therapeutic candidate for treating human cholangiocarcinoma.
\end{abstract}

\section{Introduction}

Due to the limitations in the efficacy of conventional cancer therapies, cholangiocarcinoma usually has a poor prognosis (1).

Correspondence to: Dr Xiaoping Chen, Hepatic Surgery Center, Tongji Hospital, Tongji Medical College, Huazhong University of Science and Technology, 1095 Jiefang Avenue, Wuhan, Hubei 430030, P.R. China

E-mail: chenxpchenxp@163.com

Key words: SP600125, transforming growth factor $\beta$, apoptosis, Smad, cholangiocarcinoma
To reduce the rate of cholangiocarcinoma-associated mortality, it is essential to develop therapeutics that target the signaling pathways involved in this carcinoma (2). The transforming growth factor $\beta$ (TGF- $\beta$ ) signaling pathway has become an attractive target due to its pleiotropic physiological properties in the regulation of cell proliferation, differentiation, migration, cell survival, angiogenesis and immunosurveillance (3). In response to TGF- $\beta$, receptor activation leads to the phosphorylation of cytoplasmic Smad2 and Smad3, which associates with Smad4 and translocates into the nucleus, where it regulates the transcription of TGF- $\beta$ target genes (4). Furthermore, TGF- $\beta$ induces non-Smad pathways, including phosphoinositide 3-kinases (PI3K), c-Jun N-terminal kinases (JNK), Erk, p38 mitogen activated protein kinases (MAPK) and Rho (5).

TGF- $\beta$ exhibits a dual role as either a tumor promoter or a tumor suppressor in carcinogenesis, the role is largely dependent on signals from the tumor microenvironment (6). TGF- $\beta$ responses result from Smad cascade activation and also cell-type specific interactions of Smad signaling with a variety of other intracellular signaling, which may or may not have been triggered by TGF- $\beta$ (7).

Although crosstalk between Smad and non-Smad pathways exists, the mechanism by which they regulate each other is unclear. The TGF- $\beta /$ Smad pathway may be regulated by the MAPK pathways, including the JNK pathway (8), whose inhibitor, SP600125, negatively regulates cell survival $(9,10)$. However, little is known in regard to how SP600125 affects TGF- $\beta$-induced apoptosis of human cholangiocarcinoma cells. In the present study, results show that SP600125 enhances TGF- $\beta$-induced cell apoptosis of RBE cells in a Smad-dependent manner. SP600125 is hypothesized to be an ideal therapeutic candidate for treating human cholangiocarcinomas that express JNK and Smad4.

\section{Materials and methods}

Cell cultures. The RBE human cholangiocarcinoma cell line was obtained from the Riken BioResource Center (Ibaraki, Japan). The PT67 packaging cell line was obtained from the American Type Culture Collection (Manassas, VA, USA). 
RBE cells were maintained in RPMI-1640 medium and PT67 cells were cultured in Dulbecco's modified Eagle's medium supplemented with $10 \%$ fetal bovine serum in a humidified atmosphere containing $5 \% \mathrm{CO}_{2}$ at $37^{\circ} \mathrm{C}$.

Reagents and antibodies. TGF- $\beta 1$ was purchased from R\&D Systems (Minneapolis, MN, USA). SP600125, SB203580, Wortmannin, PD98059, U0126 and SB431542 were obtained from Tocris Bioscience (Bristol, UK). V-ZAD-fmk was obtained from the Beyotime Biotech (Jiangsu, China). Antibodies against Smad2/3, p38, Akt and hlyceraldehyde 3-phosphate dehydrogenase were purchased from Santa Cruz Biotechnology, Inc. (Santa Cruz, CA, USA). Antibodies against p21, Bcl-2, Bim and Smad4 were purchased from Abcam (Cambridge, MA, USA). Antibodies against phospho-c-Jun N-terminal kinase (p-JNK), p-Akt, p-Erk, p-p38, p-Smad2 (Ser465/467), p-Smad3 (Ser423/425), p-c-Jun, JNK, Erk, c-Jun, caspase-9, cleaved caspase-9, caspase-8, cleaved caspase-8, caspase-7, cleaved caspase-7, caspase-3, cleaved caspase-3, poly ADP ribose polymerase (PARP) and cleaved PARP were purchased from Cell Signaling Technology, Inc. (Danvers, MA, USA).

Western blot analysis. Western blot analysis was performed as follows: Whole-cell extracts were prepared in lysis buffer (50 mM Tris-HCl, 10\% glycerol, $1 \%$ Triton X-100, $150 \mathrm{mM}$ $\mathrm{NaCl}, 100 \mathrm{mM}$ NaF, $5 \mathrm{mM}$ EDTA, $2 \mathrm{mM}$ phenylmethylsulfonyl fluoride, $1 \mathrm{mM}$ sodium orthovanadate and $1 \mathrm{mg} / \mathrm{ml}$ leupeptin; pH 7.5) and centrifuged (Sigma-Aldrich, St. Louis, MO, USA) at $12,000 \mathrm{x}$ g for $15 \mathrm{~min}$. Protein concentrations were measured using a bicinchoninic acid assay kit (Beyotime Biotech). Total cell proteins were subjected to electrophoresis on an $8-15 \%$ polyacrylamide gel, transferred to a nitrocellulose membrane and probed with primary antibodies overnight at $4^{\circ} \mathrm{C}$. Immunocomplexes were incubated with the appropriate horseradish peroxidase-conjugated secondary antibody and then detected using an enhanced chemiluminescent kit (Thermo Fisher Scientific, Inc., Waltham, MA, USA).

Generation of stable knockdown RBE cells. To generate recombinant retroviruses, a pRetroSuper-puro Smad4 (Addgene, Cambridge, MA, USA) was transfected into PT67 cells as described previously by $\mathrm{He}$ et al (11). A pRetroSuper-puro vector was transfected as a control. Retroviral supernatants were collected, filtered through a $0.45-\mu \mathrm{m}$ filter and used for infection of RBE cells, which were then selected with puromycin $(1 \mu \mathrm{g} / \mathrm{ml})$ for two weeks. Ultimately, RBE Smad4 negative control cells (vector control cells) and RBE Smad4 knockdown cells (shSmad4 cells) cells were obtained.

Transcriptional response assay. Cells were seeded into 12-well plates and transiently co-transfected with p3TP-Lux, (which encodes firefly luciferase) and pRL-TK-luc (which encodes Renilla luciferase). Following $48 \mathrm{~h}$ transfection, the cells were treated with the indicated reagents for an additional $24 \mathrm{~h}$ and the two luciferase activities were measured using a dual-luciferase reporter assay system (Promega Corporation, Madison, WI, USA). Relative luciferase activity was normalized with Renilla luciferase activity.
A

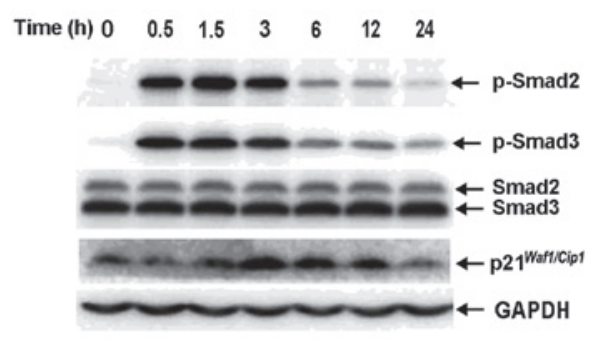

Time (h) $\begin{array}{lllllll}0 & 0.5 & 1.5 & 3 & 6 & 12 & 24\end{array}$

B

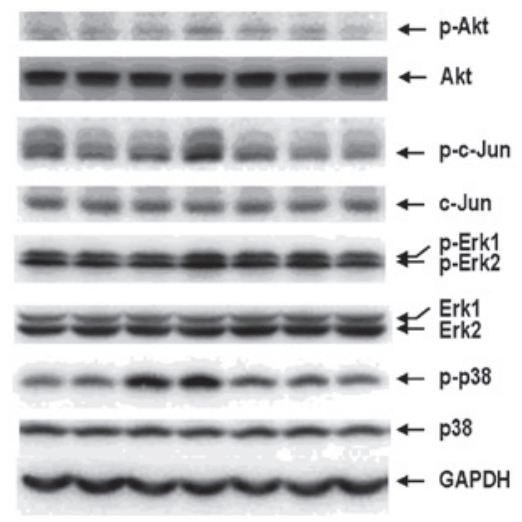

Figure 1. Exogenous TGF- $\beta 1$ activates the Smad and non-Smad pathways in RBE cells in a time-dependent manner. RBE cells were treated with TGF- $\beta 1$ $(1 \mathrm{ng} / \mathrm{ml})$ for the indicated times. Cell lysates were analyzed by western blotting with antibodies against (A) phospho-Smad2, Smad2, phospho-Smad3, Smad3, p21 Waf1/Cipl and (B) phospho-Akt, Akt, phospho-c-Jun, c-Jun, phospho-Erk1/2, Erk1/2, phospho-p38 and p38. Each experiment was repeated three times. TGF- $\beta 1$, transforming growth factor- $\beta 1$; GAPDH, glyceraldehyde 3-phosphate dehydrogenase.

Identification of apoptosis by propidium iodide(PI)-Annexin V staining. Cell apoptosis analysis was performed using an Annexin V-fluorescein isothiocyanate (FITC) apoptosis detection kit (KeyGen Biotech, Nanjing, China), according to the manufacturer's instructions. Briefly, $5 \times 10^{5}$ cells were collected by centrifugation and resuspended in $500 \mu 1$ binding buffer. Subsequently, $5 \mu \mathrm{l}$ Annexin V-FITC and $5 \mu \mathrm{l}$ PI were added. Following incubation for $10 \mathrm{~min}$ in the dark at room temperature, the cells were analyzed using a BD fluorescence-activated cell sorter Aria flow cytometer (BD Biosciences, Franklin Lakes, NJ, USA).

Statistical analysis. Data are presented as the mean \pm SD. Differences were analyzed by Student's t-test or one-way analysis of variance. $\mathrm{P}<0.05$ was considered to indicate a statistically significant difference.

\section{Results}

Exogenous TGF- $\beta 1$ activates the Smad and non-Smad pathways in RBE cells. To determine whether Smad signaling is inducible by exogenous TGF- $\beta 1$ in RBE cells, Smad 2 and Smad3 phosphorylation and the expression of $\mathrm{p} 21^{\text {Wafl/Cip1 }}$ were examined by western blot analysis. The antibodies against phosphorylated Smad2 and Smad3 used in this study specifically recognized the C-terminal region (Ser465/467 
A

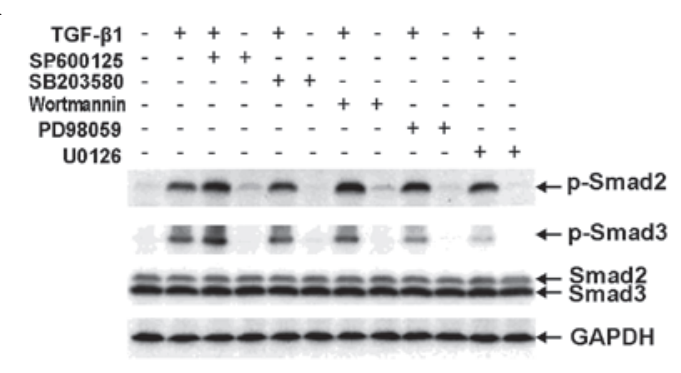

B

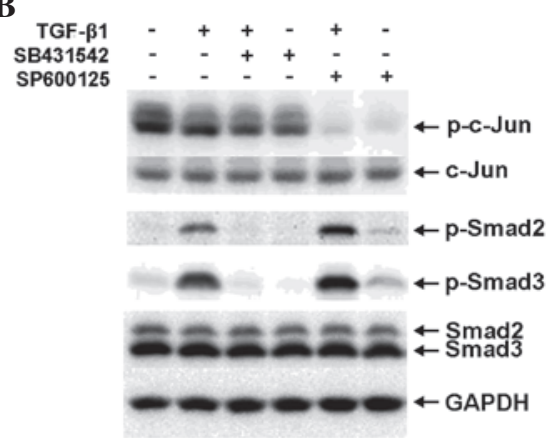

C

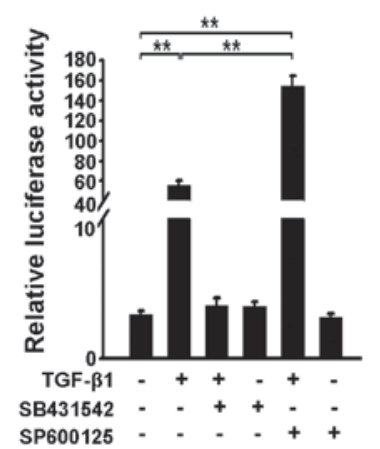

D

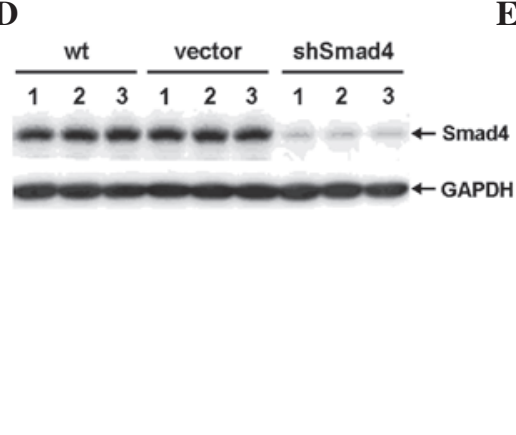

$\mathbf{E}$

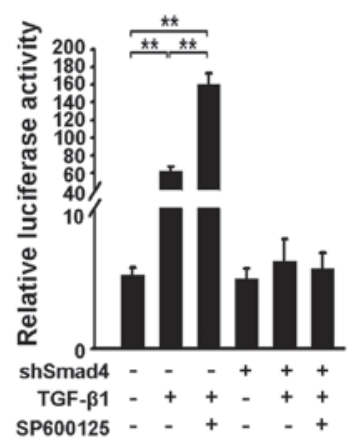

Figure 2. SP600125 increases transforming growth factor (TGF)- $\beta 1$-induced phosphorylation of Smad 2 and Smad3 and enhances TGF- $\beta /$ Smad signaling. (A) . Phospho-Smad2, phospho-Smad3 and Smad2/3 expression was examined by western blot analysis in RBE cells treated with $10 \mu \mathrm{M}$ SP600125, SB203580, Wortmannin, PD98059 or U0126 for $3 \mathrm{~h}$, with or without TGF- $\beta 1(1 \mathrm{ng} / \mathrm{ml})$. (B) Western blotting was used to determine the expression of phospho-c-Jun, c-Jun, phospho-Smad2, phospho-Smad3 and Smad2/3 in RBE cells treated with TGF- $\beta 1$ ( $1 \mathrm{ng} / \mathrm{ml}), \mathrm{SB} 431542(10 \mu \mathrm{M})$, SP600125 (10 $\mu \mathrm{M})$ or a combination of any two for $6 \mathrm{~h}$. (C) A luciferase reporter assay. p3TP-luc luciferase activity was analyzed in RBE cells treated with TGF- $\beta 1(1 \mathrm{ng} / \mathrm{ml}), \mathrm{SB} 431542(10 \mu \mathrm{M})$, SP600125 $(10 \mu \mathrm{M})$ or a combination of any two. Data are shown as the mean \pm SD for triplicate measurements. ${ }^{* *} \mathrm{P}<0.01$, vs. control. (D) Smad4 expression in three independent samples of wild-type, vector control and shSmad4 cells were examined by western blot analysis. (E) A luciferase reporter assay. p3TP-luc luciferase activity was analyzed in RBE vector control and shSmad4 cells treated with TGF- $\beta 1$ ( $1 \mathrm{ng} / \mathrm{ml})$ and/or SP600125 (10 $\mu \mathrm{M})$. Data are shown as the mean \pm SD for triplicate measurements. ${ }^{* *} \mathrm{P}<0.01$, vs. control. TGF- $\beta 1$, transforming growth facto- $\beta 1$; GAPDH, glyceraldehyde 3 -phosphate dehydrogenase; wt, wild type.

and Ser423/425). TGF- $\beta 1(1 \mathrm{ng} / \mathrm{ml})$ was observed to induce phosphorylation of Smad2 and Smad3 and the expression of p21 $1^{\text {Waf1/Cip1 }}$ in a time-dependent manner (Fig. 1A), indicating the presence of an intact TGF- $\beta$ /Smad signaling pathway in RBE cells. In addition, non-Smad pathways were activated by TGF- $\beta 1$ (Fig. 1B). There was considerable basal phosphorylation of Akt, c-Jun, Erk and p38MAPK, which transiently increased and peaked at $3 \mathrm{~h}$ following TGF- $\beta 1$ stimulation, suggesting that Akt and MAPK activation in RBE cells is not specific to TGF- $\beta$ signaling and may result from other stimuli.

The JNK inhibitor SP600125 increases TGF- $\beta 1$-induced phosphorylation of Smad2 and Smad3 and enhances TGF- $\beta /$ Smad signaling. As TGF- $\beta 1$ enhances non-Smad pathway signaling in RBE cells, it is necessary to investigate whether the non-Smad pathway affects the Smad pathway. Specific inhibitors of Akt, JNK, Erk and p38MAPK were applied to RBE cells for $3 \mathrm{~h}$ at a concentration of $10 \mu \mathrm{M}$, with or without TGF- $\beta 1$. Western blot analysis showed that only the JNK inhibitor SP600125 enhanced TGF- $\beta 1$-induced phosphorylation of Smad2 and Smad3. However, Wortmannin and PD98059 were also capable of increasing TGF- $\beta 1$-induced phosphorylation of Smad2 (Fig. 2A).

As shown in Fig. 1B, increased phosphorylation of MAPKs induced by TGF- $\beta 1$ was most evident at $3 \mathrm{~h}$ and dissipated by $6 \mathrm{~h}$. The effect of SP600125 on TGF- $\beta 1$-induced phosphorylation of Smad2 and Smad3 at $6 \mathrm{~h}$ following TGF- $\beta 1$ stimulation and obtained a similar result to that observed at $3 \mathrm{~h}$ (Fig. 2A and B). This result suggests that the basal activity of the JNK pathway, rather than the TGF- $\beta 1$-induced activity, antagonizes TGF- $\beta 1$-induced phosphorylation of Smad 2 and Smad3.

In the absence of TGF- $\beta 1$, SP600125 only marginally enhanced the phosphorylation of Smad 2 and Smad3 compared with the control. However, the combined application of SP600125 and TGF- $\beta 1$ significantly increased TGF- $\beta 1$-induced phosphorylation of Smad2 and Smad3 (Fig. 2B). These results suggest that the effect of SP600125 on the Smad pathway may be dependent upon the activity of the Smad pathway.

To determine whether SP600125 affects downstream signaling, an additional application of SP600125 was observed to strengthen TGF- $\beta 1$-induced p3TP-Lux reporter activity (Fig. 2C). In addition, to elucidate whether the effect of SP600125 on TGF- $\beta$ signaling is dependent on the canonical Smad pathway, a Smad4 knockdown RBE cell line (shSmad4 cells) was developed (Fig. 2D), which resulted in the reduced effect of SP600125 on TGF- $\beta 1$-induced reporter activity (Fig. 2E).

Exogenous TGF- $\beta 1$ induces apoptosis of RBE cells by activating the caspase cascade through the Smad pathway. As shown in Fig. 3A-D, exogenous TGF- $\beta 1$ induces apoptosis of RBE cells in a dose- and a time-dependent manner. The observed apoptosis was prominent in cells treated with $1 \mathrm{ng} / \mathrm{ml} \mathrm{TGF}-\beta 1$ 


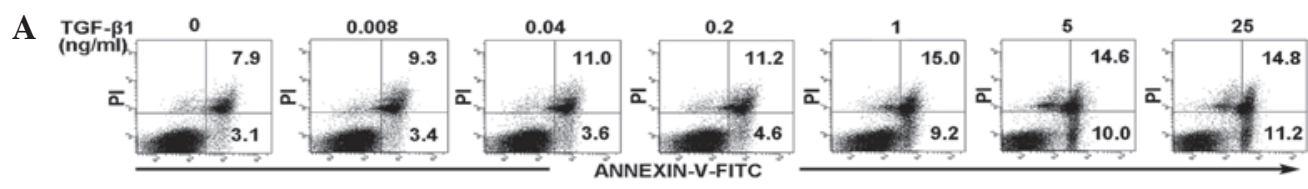

B
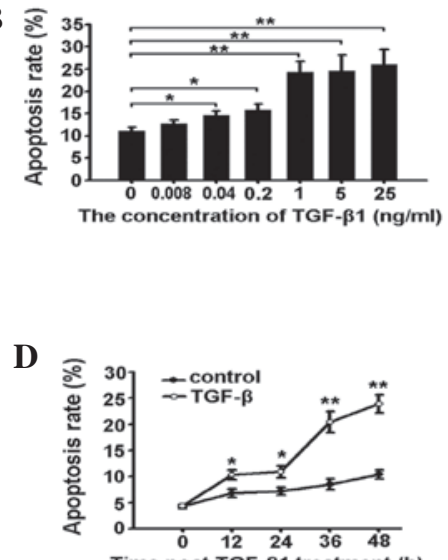

Time post TGF- $\beta 1$ treatment (h)
C

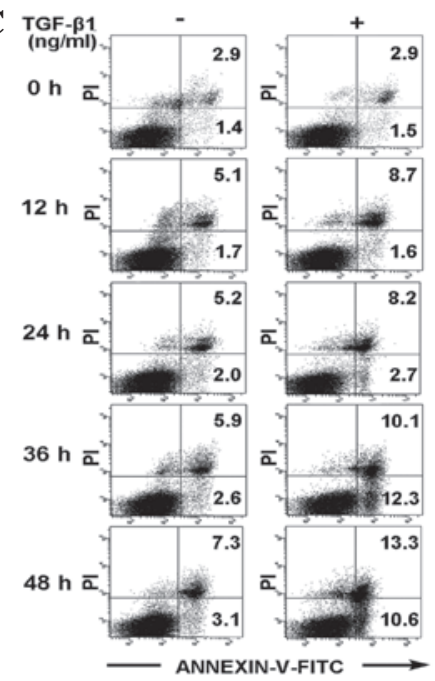

$\mathbf{E}$

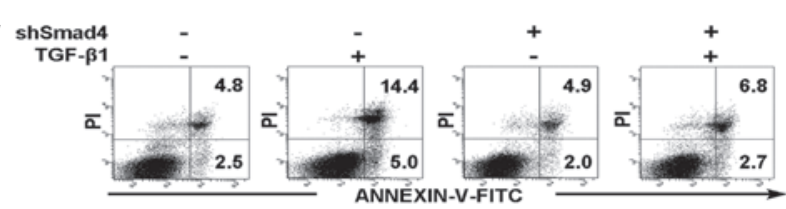

F

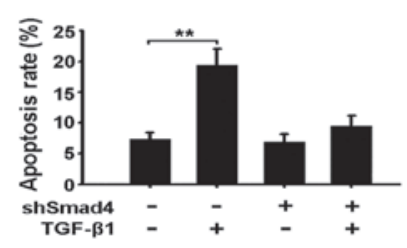

G

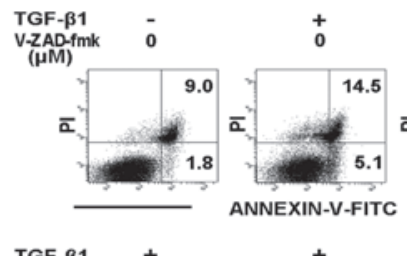

$\stackrel{+}{+}$

$\stackrel{+}{20}$
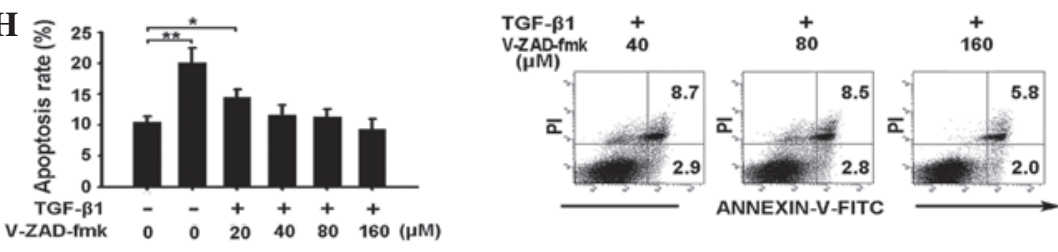

I

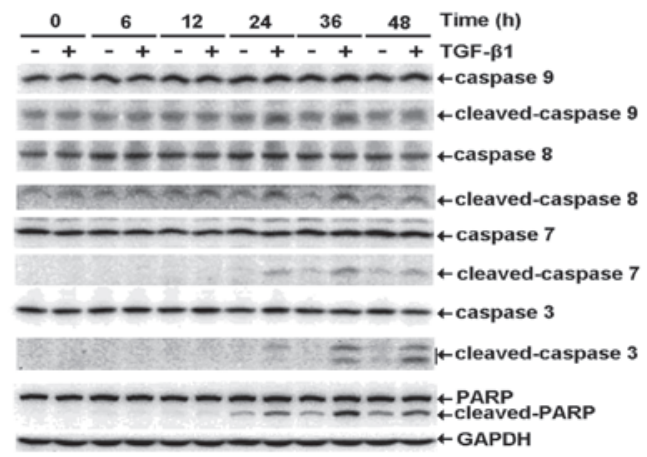

Figure 3. Exogenous TGF- $\beta 1$ induces apoptosis of RBE cells by activating the caspase cascade through the Smad pathway. (A and B) RBE cells treated with various concentrations of TGF- $\beta 1$ for $36 \mathrm{~h}$ were stained with Annexin V/PI and analyzed by flow cytometry. (A) The early apoptotic rate (lower right) and the late apoptotic rate (upper right) are shown. (B) Total apoptotic rates (the sum of the early and late apoptotic rate) are shown as the mean \pm SD from triplicate measurements. ${ }^{*} \mathrm{P}<0.05$, vs. control and ${ }^{* *} \mathrm{P}<0.01$, vs. control. (C and D) RBE cells were treated with TGF- $\beta 1$ ( $\left.1 \mathrm{ng} / \mathrm{ml}\right)$ for $0,12,24,36$ and $48 \mathrm{~h}$. The apoptotic rates were analyzed by $(\mathrm{C})$ flow cytometry and (D) the total apoptotic rates are shown as the mean \pm SD from triplicate measurements. "P $<0.05$, vs. control, ${ }^{* *} \mathrm{P}<0.01$, vs. control. (E and F) Vector control and shSmad4 cells were treated with TGF- $\beta 1(1 \mathrm{ng} / \mathrm{ml})$ for $36 \mathrm{~h}$. The apoptotic rates were analyzed by (E) flow cytometry and $(\mathrm{F})$ the total apoptotic rates are shown as the mean $\pm \mathrm{SD}$ from triplicate measurements. ${ }^{* *} \mathrm{P}<0.05$, vs. control. (G and $\left.\mathrm{H}\right) \mathrm{RBE}$ cells were treated with TGF- $\beta 1(1 \mathrm{ng} / \mathrm{ml})$ in combination with different concentrations of V-ZAD-fmk for $36 \mathrm{~h}$. (G) The apoptotic rates were analyzed by flow cytometry and $(\mathrm{H})$ the total apoptotic rates are shown as the mean $\pm \mathrm{SD}$ from triplicate measurements. ${ }^{*} \mathrm{P}<0.05$, vs. control and ${ }^{* *} \mathrm{P}<0.01$, vs. control. (I) RBE cells were treated with or without TGF- $\beta 1(1 \mathrm{ng} / \mathrm{ml})$ for the indicate times and cell lysates were analyzed by western blot analysis with antibodies against the proteins indicated. The experiment was repeated three times. TGF- $\beta 1$, transforming growth factor- $\beta 1$; GAPDH, glyceraldehyde 3-phosphate dehydrogenase; FITC, fluorescein isothiocyanate; .PI, propidium iodide; PARP, poly ADP ribose polymerase. 

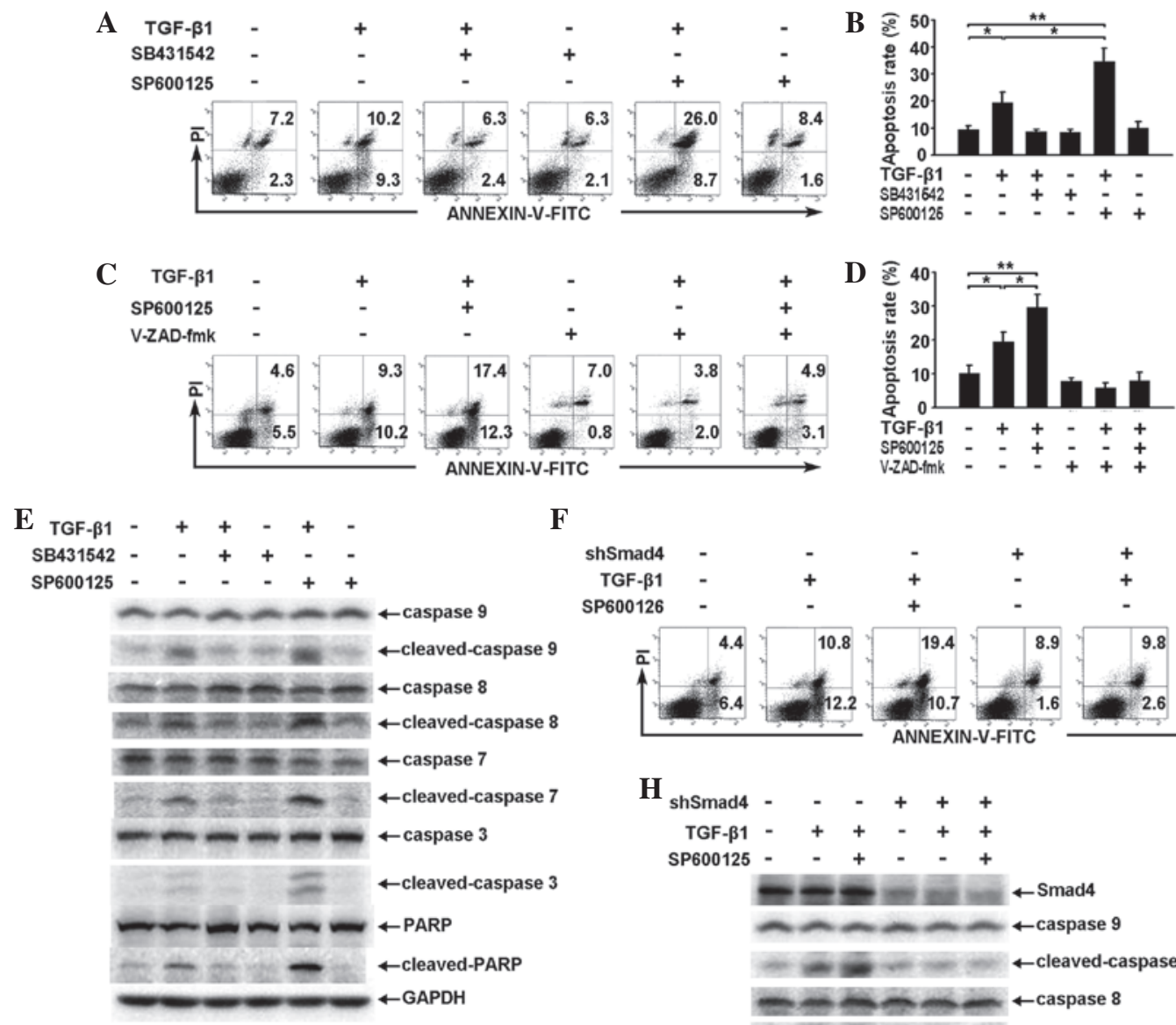

V-ZAD-Imk - - +++
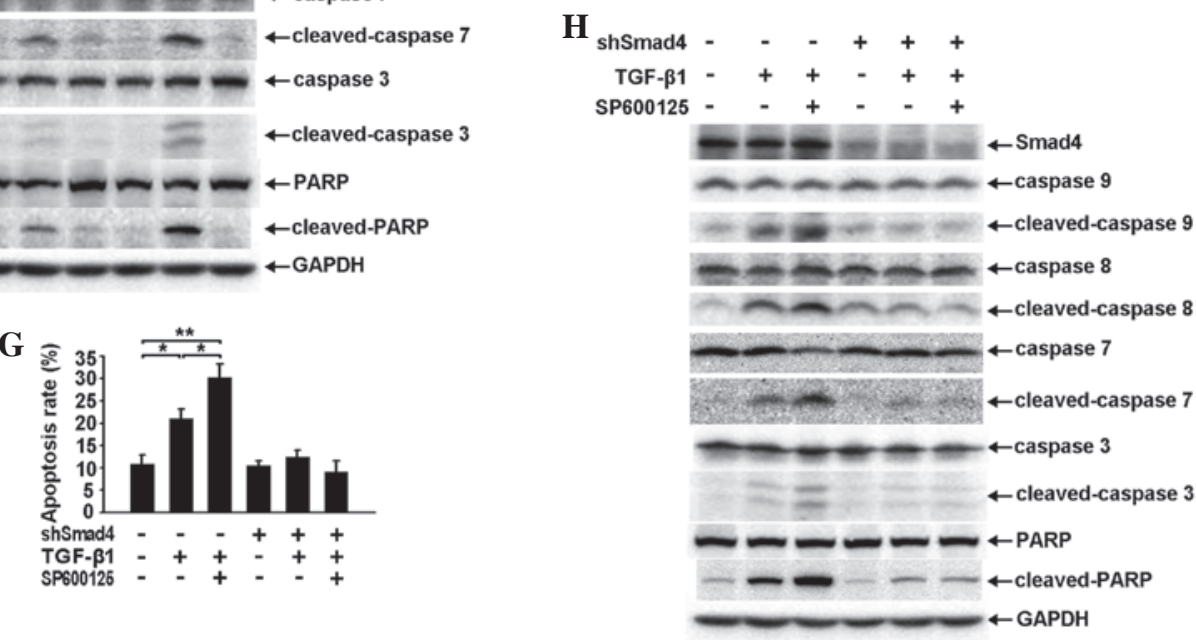

Figure 4. SP600125 enhances TGF- $\beta 1$-induced apoptosis of RBE cells by enhancing the activation of the caspase cascade through the Smad pathway. (A and B) RBE cells were treated with TGF- $\beta 1(1 \mathrm{ng} / \mathrm{ml}), \mathrm{SB} 431542(10 \mu \mathrm{M})$, SP600125 $(10 \mu \mathrm{M})$ or a combination of any two for $36 \mathrm{~h}$. The apoptotic rates were analyzed by (A) flow cytometry and (B) the total apoptotic rates are shown as the mean $\pm \mathrm{SD}$ from triplicate measurements. ${ }^{*} \mathrm{P}<0.05$, vs. control, ${ }^{* *} \mathrm{P}<0.01$, vs. control. (C and D) RBE cells were treated with TGF- $\beta 1(1 \mathrm{ng} / \mathrm{ml})$ and/or SP600125 $(10 \mu \mathrm{M})$ for $36 \mathrm{~h}$ in the presence or absence of V-ZAD-fmk $(40 \mu \mathrm{M})$. The apoptotic rates were analyzed by $(\mathrm{C})$ flow cytometry and (D) the total apoptotic rates are shown as the mean \pm SD from triplicate measurements. $\mathrm{P}<0.05$, vs. control, ${ }^{* *} \mathrm{P}<0.01$, vs. control. (E) RBE cells were treated with TGF- $\beta 1(1 \mathrm{ng} / \mathrm{ml}), \mathrm{SB} 431542(10 \mu \mathrm{M}), \mathrm{SP} 600125(10 \mu \mathrm{M})$ or a combination of any two for $36 \mathrm{~h}$. Cell lysates were analyzed by western blotting with antibodies against the proteins indicated. The experiment was repeated three times. (F-H) Vector control and Smad4 cells were treated with TGF- $\beta 1(1 \mathrm{ng} / \mathrm{ml})$ and/or SP600125 $(10 \mu \mathrm{M})$ for $36 \mathrm{~h}$. The apoptotic rates were analyzed by (F) flow cytometry and $(\mathrm{G})$ The total apoptotic rates are shown as the mean \pm SD from triplicate measurements, ${ }^{*} \mathrm{P}<0.05$, vs. control, ${ }^{* *} \mathrm{P}<0.01$, vs. control. (H) Cell lysates were subjected to western blotting using antibodies against the proteins indicated. All assays were performed in triplicate. TGF, transforming growth factor. TGF- $\beta 1$, transforming growth factor- $\beta 1$; GAPDH, glyceraldehyde 3-phosphate dehydrogenase; FITC, fluorescein isothiocyanate; .PI, propidium iodide; PARP, poly ADP ribose polymerase.

for $36 \mathrm{~h}$. Specific knockdown of Smad4 expression reduced TGF- $\beta 1$-induced apoptosis, suggesting that apoptosis occurs through a Smad-dependent pathway (Fig. 3E and F). To confirm whether caspase activation occurs during TGF- $\beta 1$-induced apoptosis, the effect of the pan-caspase inhibitor, V-ZAD-fmk, on the induction of apoptosis was investigated. As expected, 40, 80 and $160 \mu \mathrm{M}$ V-ZAD-fmk completely inhibited the TGF- $\beta 1$-induced apoptosis of RBE cells (Fig. 3G and $\mathrm{H}$ ). This result suggests that caspase activation is required for TGF- $\beta 1$-induced apoptosis. Accordingly, western blot analysis showed that the activation of caspase- $9,-8,-7$ and -3 , and PARP was prominent at $36 \mathrm{~h}$, the time at which apoptosis of the RBE cells was observed (Fig. 3I).

SP600125 enhances TGF- $\beta 1$-induced apoptosis of RBE cells by enhancing the activation of the caspase cascade through the Smad pathway. With regard to the effect on TGF- $\beta / S m a d$ pathway signaling (Fig. 2A and B), application of SP600125 alone exhibited a minimal effect on the apoptosis of RBE cells but was capable of significantly enhancing TGF- $\beta 1$-induced apoptosis when combined with TGF- $\beta 1$ (Fig. 4A and B). 
The pan-caspase inhibitor V-ZAD-fmk inhibited TGF- $\beta 1$-induced apoptosis and also reduced the effect of SP600125 on TGF- $\beta 1$-induced apoptosis (Fig. 4C and D). These results suggest that caspase activation is also required for the regulation of TGF- $\beta 1$-induced apoptosis by SP600125. Similarly, western blot analysis showed that SP600125 strengthened TGF- $\beta 1$-induced activation of the caspase cascade and PARP (Fig. 4E).

In addition, PI-Annexin V staining showed that specific knockdown of Smad4 expression resulted in a phenotype similar to that observed following V-ZAD-fmk treatment (Fig. 4F and G). Furthermore, activation of the caspase cascade and PARP induced by TGF- $\beta 1$ or by TGF- $\beta 1$ and SP600125 was observed to be reduced following specific knockdown of Smad4 expression (Fig. 4H), suggesting that SP600125 enhances TGF- $\beta 1$-induced apoptosis of RBE cells through a Smad-dependent pathway, which is located upstream of the caspase cascade.

\section{Discussion}

Cholangiocarcinoma is one of the most aggressive types of malignancies worldwide due to its early relapse or metastasis following surgery, poor survival and limited sensitivity to chemotherapy (1). Therefore, novel therapeutic strategies require urgent investigation to improve prognosis. Currently, attention is focused on signaling pathways involved in tumor development and progression. The TGF- $\beta$ signaling pathway is pivotal in different types of tumors and a number of inhibitors targeting the TGF- $\beta$ signaling pathway have been studied in pre-clinical research (12). JNK is a component of the non-Smad signaling pathway, which is important in tumor progression and chemosensitivity (13). In the current study, the mechanism by which SP600125 regulates TGF- $\beta$-induced cell apoptosis in cholangiocarcinoma in vitro was investigated.

TGF- $\beta$ acts as a potent tumor suppressor or tumor promoter in a context-dependent manner. The tumor suppressive functions of TGF- $\beta$ are largely ascribed to its ability to inhibit proliferation and induce apoptosis. During carcinogenesis, a number of cancer cell types, including pancreatic, breast and colorectal carcinoma cells, frequently become unresponsive to the inhibitory growth effects of TGF- $\beta$, due to a loss or mutation of one of the components of the TGF- $\beta$ signaling pathway, which facilitates the transition of TGF- $\beta$ from a tumor suppressor to a tumor promoter (14). However, the majority of types of cancer do not have mutations in the TGF- $\beta$ pathway, suggesting that TGF- $\beta$ signaling may be functional as a tumor suppressor in those cells. In the current study exogenous TGF- $\beta 1$ was observed to act as a tumor suppressor and induce phosphorylation of Smad2 and Smad3 in the RBE human cholangiocarcinoma cell line, which results in apoptosis of these cells through a Smad-dependent pathway. In this context, enhancing the tumor-suppressive activity of TGF- $\beta$ provides a potential therapeutic strategy for treating cholangiocarcinoma.

The JNK pathway is associated with cell survival $(15,16)$ and was reported to interfere with the TGF- $\beta$ pathway $(17,18)$. In the present study, the activation of the Smad pathway by exogenous TGF- $\beta 1$ in RBE cells was partially inhibited by the JNK pathway, which had considerable basal activity that was increased transiently by TGF- $\beta 1$. It is possible that the basal activity of the JNK pathway, rather than the TGF- $\beta 1$-induced activity, antagonizes the TGF- $\beta /$ Smad pathway in RBE cells. Therefore, the JNK inhibitor SP600125 may restore the reduced tumor-suppressor function of TGF- $\beta$ in RBE cells.

Smad 2 and Smad3 may be phosphorylated at two sites, namely, the most common C-terminal region and the previously reported linker region (19). Matsuzaki et al $(20,21)$ and Murata et al (22) reported that during the development of human colorectal cancer and hepatocellular carcinoma, JNK activation antagonized the tumor-suppressive TGF- $\beta$ pathway by reducing the phosphorylation of $\mathrm{Smad} 2$ and $\mathrm{Smad} 3$ at the C-terminal region (pSmad2C and $\mathrm{pSmad} 3 \mathrm{C}$ ) and augmented the oncogenic activities of TGF- $\beta$ by enhancing phosphorylation in the linker region $(\mathrm{pSmad} 2 \mathrm{~L}$ and $\mathrm{pSmad} 3 \mathrm{~L})$. The current study observed that there was no change in the TGF- $\beta 1$-induced phosphorylation of Smad2 and Smad3 at the linker region in RBE cells when the JNK pathway was blocked using SP600125 (data not shown). This result suggests that $\mathrm{pSmad} 2 \mathrm{~L}$ and $\mathrm{pSmad} 3 \mathrm{~L}$ are not involved in the effect of JNK on the TGF- $\beta /$ Smad pathway in RBE cells. By contrast, SP600125 increased the TGF- $\beta 1$-induced phosphorylation of Smad2 and Smad3 at the C-terminal region (Ser465/467 and Ser423/425), augmented the TGF- $\beta 1$-induced transcriptional response through the Smad pathway and enhanced TGF- $\beta 1$-induced apoptosis of RBE cells dependent on the Smad pathway. Collectively, the results indicate that TGF- $\beta$ functions as a tumor suppressor through the activation of the Smad pathway, in particular, the phosphorylation of Smad2 and Smad3 at the C-terminal region. SP600125 enhances the tumor-suppressive function of TGF- $\beta$, possibly by augmenting phosphorylation of Smad2 and Smad3 and TGF- $\beta$-induced transcriptional activity.

The mechanism by which the JNK inhibitor enhances the tumor-suppressive activity of TGF- $\beta$ through the Smad pathway was investigated. Activation of the caspase cascade by cleavage is the most basic molecular event in apoptosis (23). In the present study, the requirement for caspase activation during TGF- $\beta 1$-induced apoptosis of RBE cells was confirmed by the pan-caspase inhibitor, Z-VAD-fmk. TGF- $\beta 1$ was observed to activate the caspase cascade through a Smad-dependent pathway. Furthermore, SP600125 enhanced TGF- $\beta 1$-initiated activation of the caspase cascade and this effect was also Smad dependent, which is consistent with the regulation of TGF- $\beta /$ Smad signaling by SP600125. These results further support the hypothesis that SP600125 enhances the tumor-suppressive function of TGF- $\beta$ through activation of the Smad pathway and the downstream caspase cascade.

SP600125 was observed to augment the anti-proliferative effect of TGF- $\beta$ in RBE cells (data not shown). However, this effect is not associated with Smad4 expression (data not shown), suggesting that other pathways, rather than the Smad-dependent pathway, are involved in the anti-proliferative effect of SP600125 in RBE cells.

In conclusion, this study demonstrated that SP600125 enhances TGF- $\beta$-induced apoptosis in RBE cells through Smad-dependent caspase activation. Future studies may focus on the therapeutic effect of SP600125 in animal models as it is hypothesized to be an ideal therapeutic candidate for treating cholangiocarcinoma clinically. 


\section{Acknowledgements}

The authors would like to thank Hongwu Wang for his assistance with the flow cytometry analysis. This study was supported by grants from the State Key Project on Inflectional Disease of China (grant no. 2012ZX10002016-004 and 2012ZX10002010-001-004) and the Chinese Ministry of Public Health for Key Clinical Projects (grant no. 439, 2010) to Dr Xiaoping Chen and the National Nature Science Foundation of China (grant nos. 30973498 and 81072001) to Dr Bixiang Zhang.

\section{References}

1. Khan SA, Thomas HC, Davidson BR and Taylor-Robinson SD: Cholangiocarcinoma. Lancet 366: 1303-1314, 2005.

2. Sia D, Tovar V, Moeini A and Llovet JM: Intrahepatic cholangiocarcinoma: pathogenesis and rationale for molecular therapies. Oncogene: Jan 14, 2013 (Epub ahead of print).

3. Massagué J, Blain SW and Lo RS: TGFbeta signaling in growth control, cancer, and heritable disorders. Cell 103: 295-309, 2000

4. Shi Y and Massagué J: Mechanisms of TGF-beta signaling from cell membrane to the nucleus. Cell 113: 685-700, 2003.

5. Derynck $R$ and Zhang YE: Smad-dependent and Smad-independent pathways in TGF-beta family signalling. Nature 425: 577-584, 2003.

6. Massague J: TGF $\beta$ signalling in context. Nat Rev Mol Cell Biol 13: 616-630, 2012.

7. Javelaud D and Mauviel A: Crosstalk mechanisms between the mitogen-activated protein kinase pathways and Smad signaling downstream of TGF-beta: implications for carcinogenesis Oncogene 24: 5742-5750, 2005.

8. Liu Q, Zhang Y, Mao H, et al: A crosstalk between the Smad and JNK signaling in the TGF- $\beta$-induced epithelial-mesenchyma transition in rat peritoneal mesothelial cells. PLoS One 7: e32009, 2012.

9. Kuntzen C, Sonuc N, De Toni EN, et al: Inhibition of c-Jun-N-terminal-kinase sensitizes tumor cells to CD95-induced apoptosis and induces G2/M cell cycle arrest. Cancer Res 65: 6780-6788, 2005.
10. Shaulian E and Karin M: AP-1 in cell proliferation and survival. Oncogene 20: 2390-2400, 2001.

11. He W, Dorn DC,Erdjument-Bromage H, Tempst P, Moore MA and Massagué J: Hematopoiesis controlled by distinct TIF1gamma and Smad4 branches of the TGFbeta pathway. Cell 125: 929-941, 2006.

12. Akhurst RJ and Hata A: Targeting the TGF $\beta$ signalling pathway in disease. Nat Rev Drug Discov 11: 790-811, 2012.

13. Vasilevskaya I and O'Dwyer PJ: Role of Jun and Jun kinase in resistance of cancer cells to therapy. Drug Resist Updat 6: 147-156, 2003.

14. Inman GJ: Switching TGF $\beta$ from a tumor suppressor to a tumor promoter. Curr Opin Genet Dev 21: 93-99, 2011.

15. Davis RJ: Signal transduction by the JNK group of MAP kinases. Cell 103: 239-252, 2000.

16. Hess P, Pihan G, Sawyers CL, Flavell RA and Davis RJ: Survival signaling mediated by c-Jun NH(2)-terminal kinase in transformed B lymphoblasts. Nat Genet 32: 201-205, 2002.

17. Brown JD, DiChiara MR, Anderson KR, Gimbrone MA Jr and Topper JN: MEKK-1, a component of the stress (stress-activated protein kinase/c-Jun $\mathrm{N}$-terminal kinase) pathway, can selectively activate Smad2-mediated transcriptional activation in endothelial cells. J Biol Chem 274: 8797-8805, 1999.

18. Engel ME, McDonnell MA, Law BK and Moses HL: Interdependent SMAD and JNK signaling in transforming growth factor-beta-mediated transcription. J Biol Chem 274: 37413-37420, 1999.

19. Mori S, Matsuzaki K, Yoshida K, et al: TGF-beta and HGF transmit the signals through JNK-dependent Smad2/3 phosphorylation at the linker regions. Oncogene 23: 7416-7429, 2004

20. Matsuzaki K, Murata M, Yoshida K, et al: Chronic inflammation associated with hepatitis $C$ virus infection perturbs hepatic transforming growth factor beta signaling, promoting cirrhosis and hepatocellular carcinoma. Hepatology 46: 48-57, 2007.

21. Matsuzaki K, Kitano C, Murata M, et al: Smad2 and Smad3 phosphorylated at both linker and $\mathrm{COOH}$-terminal regions transmit malignant TGF-beta signal in later stages of human colorectal cancer. Cancer Res 69: 5321-5330, 2009.

22. Murata M, Matsuzaki K, Yoshida K, et al: Hepatitis B virus $\mathrm{X}$ protein shifts human hepatic transforming growth factor (TGF)-beta signaling from tumor suppression to oncogenesis in early chronic hepatitis B. Hepatology 49: 1203-1217, 2009.

23. Grütter MG: Caspases: key players in programmed cell death. Curr Opin Struct Biol 10: 649-655, 2000. 